\title{
NEUROLINGUISTIK PROGRAMING DALAM BIDANG PENDIDIKAN
}

\author{
Devita Cahyani Nugraheny', Arie Purwa Kusuma² \\ STKIP Kusuma Negara Jakarta \\ devita cahyani@stkipkusumanegara.ac.id ${ }^{1}$ \\ Arie pk@stkipkusumanegara.ac.id ${ }^{2}$
}

\begin{abstract}
Abstrak
Melalui pendidikan, peserta didik memperoleh informasi dan pengetahuan yang dapat dipergunakan untuk mengembangkan diri sesuai dengan kemampuan dan kesempatan yang ada. Pendidikan mempersiapkan peserta didiknya untuk siap menjadi anggota masyarakat yang memiliki keterampilan hidup dan menerapkan dan mengembangkan ilmu pengetahuan dan teknologi. Namun dalam proses pelaksanaan pendidikan, tidak terlepas dari permasalahan yang kompleks seperti kejenuhan dalam belajar, kurangnya percaya diri dalam berinteraksi antar peseserta didik baik individu maupun kelompok, kecemasan menghadapi ujian sekolah, rendahnya motivasi belajar peserta didik, penundaan tugas belajar, dan masih banyak lagi permasalahan lainnya. Berbagai masalah tersebut dapat diatasi dengan menggunakan teknik Neuro-Linguistic Programming (NLP). NLP merupakan sebuah pendekatan yang memungkinkan mengatasi masalah-masalah yang dilakukan dengan cepat dan bersahabat. Aplikasi NLP dengan menggunakan pendekatan khas bawah sadarsehingga berlangsung cepat. Teknik NLP ini juga bersahabat, karena anak sering kali tidak merasa sedang diajari atau diberitahu.
\end{abstract}

Kata kunci: NLP, Pendidikan

\section{PENDAHULUAN}

Pendidikan merupakan suatu usaha perbaikan, agar berkehidupan menjadi lebih baik dan diharapkan dapat mempercepat kemajuan suatu bangsa saat ini. Sebagaimana fungsi pendidikan itu sendiri agar dapat memberikan perubahan yang inovatif (Syamsul Hidayat, 2016) . Proses pendidikan tidak selamanya berjalan mulus, kadang banyak hambatan yang ditemui oleh guru dan peserta didik.

Mengatasi masalah-masalah tersebut dapat diterapkan dengan mengunakan sebuah teknik, yaitu NeuroLinguistic Programming (NLP). NLP merupakan suatu program komunikasi yang dikembangkan berdasarkan pendekatan hypnoterapi dan psikoterapi. NLP dimulai dengan mempelajari dan membahas komunikasi manusia yang sistematis. (O'Connor, 2001).NLP sangat efektif diterapkandalam bidang pendidikan, konseling, bisnis dan terapi (O'Connor \& Seymour, 1990). Hasil penelitian yang dilakukan oleh Albalawi (2014) menunjukan teknik-teknik dalam NLP efektif dalam meningkatkan kualitas hidup mahasiswa. Selanjutnya, strategi penggunaan pelatihan NLP berpengaruh terhadap tingkat kecemasan, dalam 
artian menurunkan kecemasan. Hasil penelitian Lashkarian \& Sayadian (2015) menunjukan teknik-tenik dalam NLP dapat meningkatkan motivasi dan prestasi bahasa peserta didik serta hasil analisis isi dari wawancara menunjukan bahwa teknik NLP efektif dalam pengajaran.

Berdasarkan beberapa penelitian yang telah dilakukan terbukti bahwa penerapan teknik NLP efektif dalam bidang pendidikan.

\section{KAJIAN PUSTAKA}

\section{Perkembangan Terapi}

Menurut Skinner dan Croft, 2009 (dalam Davies, 2009). Neuro Linguistic Program yang selanjutnya disingkat NLP terdiri dari kata "neuro", "linguistic", "programming". Neuro mengacu kepada istilah neurologi yang berarti pola-pola berfikir. "Linguistic" adalah bahasa, baik dalam menggunakannya maupun dipengaruhi oleh bahasa itu sendiri. "Programming" mengacu kepada perilaku dan tujuantujuan yang kita bentuk NLP menurut Bandler \& Grinder, individu adalah suatu keseluruhan sistem pikiran-tubuh dengan hubungan yang telah dipola diantara pengalaman internal (neuro), bahasa (language), dan perilaku (Programming) (Tosey, 2005; Huehls, 2010; Seyhener, 2011) Dengan mempelajari hubungan-hubungan tersebut, individu secara efektif bertransformasi dari cara lama mereka dalam merasakan, berfikir, dan berperilaku, menjadi bentuk baru dan jauh lebih membantu dalam komunikasi manusia.

Respon untuk berkomunikasi akan lebih baik positif jika disajikan oleh individu dalam menggunakan bahasa yang mencerminkan cara yang paling disukai dalam melihat dunia (Huehls, 2010 ; Seyhener, 2011). NLP dikenal sebagai metode untuk berkomunikasi dan pengembangan pribadi (Tosey, 2005) atau proses modeling (Stipanic, 2010).

Menurut Bandler \& Grinder dalam (Davies, 2009). karena hal-hal tersebut, dua individu menerima satu dunia melalui sistem-sistem yang berbeda akan memiliki pengalaman yang berbeda terhadap dunia. ituNlP adalah psikoterapi yang memungkinkan individu untuk membuka struktur komunikasi manusia. Dengan menerapkan NLP diharapkan individu dapat merasakan, berfikir, komunikasi, dan memanajemen diri dengan lebih efektif (Seyner, 2011).

\section{Istilah NLP (NeuroLinguitic} Programming) digunakan pertama kali oleh Richard Bandler dan John Grinder pada pertengahan tahun 1970 di Universitas California Santa Cruz. Mereka belajar dari beberapa ahli yang diantaranya Virginia Satir terapis keluarga, Fritz Perls psikotrapis beraliran Gestalt, dan Milton H. Erickson praktisi hipnoterapi (Ready \& Burton, 
2010). Setelah belajar dari para ahli Richard Bandler dan John Grinder mengembangkan terapi dengan istilah NeuroLinguitic Programming (NLP).

NLP muncul dari kajian mengenai struktur pengalaman individu secara detail, khususnya yang berfokus pada orang-orang yang luar biasa pada bidangnya (Palmer, 2000). NLP merupakan seni dan ilmu dari pribadi yang unggul. Istilah seni dikarenakan setiap individu memiliki keunikan dan gaya mengenai apa yang dilakukan O'Connor \& Seymour (1990).

Istilah ilmu dikarenakan terdapat sebuah metode dan proses untuk menemukan pola yang digunakan oleh individu untuk mencapai hasil. Selanjutnya Knight (2002) menambahkan NLP adalah kajian mengenai apa yang terjadi dalam pemikiran, bahasa, dan perilaku setiap individu sehingga memungkinkan untuk mencapai hasil yang diinginkan dalam kehidupan.

Berdasarkan beberapa pendapat tersebut NLP adalah seni dan ilmu yang mengkaji tentang pikiran, bahasa, dan perilaku individu dalam mencapai hasil yang diinginkan

\section{Konsep Dasar}

NLP terdiri dari dari tiga area. Neuro berkaitan dengan pikiran, Linguistic, berkaiatan dengan penggunaan bahasa dan pengaruhnya dan Programming, rangkaian dari tindakan untuk mencapai tujuan
(O'Connor, 2001). Beberapa prinsip dalam NLP antara lain: keakraban, sensor kesadaran, berorientasi pada hasil, dan fleksibilitas

Keakraban (rapport) adalah salah satu prinsip terpenting dalam NLP maupun bentuk terapi psikologi lainnya. Rapport dibentuk dalam kualitas hubungan yang didasari pada kepercayaan bersama, kepedulian, saling memahami antar individu ( $\mathrm{O}^{\prime}$ Connor, 2001). Tentunya proses menyelesaikan masalah akan berjalan dengan efektif dan efisienapabila ada keakraban telah terjalin antara guru dengan peserta didik.

Sensor kesadaran (awareness) mencakup lima panca indera yang digunakan oleh setiap individu. Tentunya sensor kesadaran setiap individu akan berbeda dengan individu lainnya. Hal ini dikarenakan banyaknya informasi dari kenyataan (dunia eksternal) akan digeneralisir, distorsi, bahkan dihapus oleh persepsi (dunia internal) setiap individu. Hal ini dikenal dengan istilah map is not the territory atau presuposisi dalam NLP. Maksudnya adalah kejadian sesungguhnya tidak akan pernah sama dengan kejadian didalam pikiran atau persepsi setiap individu. Setiap individu akan merespon berdasarkan persepsi akan kenyataan yang dihadapi (Palmer, 2000)

Berorientasi pada hasil (outcome) memberikan kejelasan terhadap sesuatu yang ingin dicapai seperti membuat 
keputusan, pilihan karir, penyelesaian tugas sekolah dan sebagainya. O'Conor (2001) menekankan pada tiga dasar dalam proses orientasi pada hasil meliputi mengetahui situasi saat ini, situasi yang diinginkan, dan merencanakan strategi tindakan melalui potensi yang dimiliki. Setiap individu diharapkan dapat menentukan dengan jelas tujuan yang ingin dicapai dalam kehidupan. Layaknya seorang yang berkendara ke suatu tempat dan ia seharusnya telah paham akan tempat yang ingin dituju tersebut apakah itu rumah, kantor, sekolah, dan sebagainya, karena masing-masing tempat membutuhkan perencanaan atau persiapan yang berbeda-beda.

Fleksibilitas (flexibility) dalam NLP berkaitan dengan prilaku (Ready \& Burton, 2010). Fleksibilitas dalam perilaku yaitu melakukan sesuatu yang berbeda ketika peristiwa yang terjadi tidak sesuai dengan yang direncakan atau diharapkan.

\section{Teknik dalam NLP}

Beberapa teknik dalam NLP yang dapat diterapkan adalah reframing, anchoring,building rapport, six step framing Reframing

(membingkai) O'Connor (2001) menyatakan framing atau kerangka berpikir merupakan pemaknaan yang disebabkan oleh suatu peristiwa dalam suatu konteks. Pintos \& López (2010) menambahakan makna dari suatu peristiwa atau situasi tergantung dari sudut pandang setiap individu. Teknik reframing dengan membuat kerangka berpikir atau mengatur situasi baru untuk menghasilkan makna baru yang diinginkan.

Anchoring (tombol) menuliskan anchoring merupakan bagaimana cara memperoleh kondisi yang tepat untuk hasil yang diinginkan dengan cara menghubungkan dengan sebuah simbol. Teknik ini juga yang menghubungkan antara apa yang dilihat, dengar, rasakan serta kondisi emosional seseorang (Lashkarian \& Sayadian, 2015). Sederhananya anchor adalah pemicu dari kondisi seseorang secara internal maupun eksternal. Dalam istilah psikologi anchor dikenal dengan stimulus. Teknik ini menerapkan struktur pikiran atau emosi tertentu termasuk kondisi relaks, dan bahagia (Albalawi, 2014). Pada umumnya melibatkan sentuhan, gerakan atau katakata sebagai anchor.

Building rapport (keakraban) Sebagaimana diketahui dalam proses penyelesain masalah building rapport (keakraban) adalah bagian terpenting. Hal ini bertujuan agar konseli dapat terbuka, nyaman, dan percaya terhadap konselor sehingga dapat mengukapkan permasalahan yang dihadapi. O'connor (2001) menyatakan rapport merupakan kualitas hubungan yang saling mempengaruhi dan peduli diantara setiap orang. Sementara itu dalam NLP terdapat salah satu teknik dalam building 
rapport, yaitu mirror and matching (meniru dan menyesuiakan) suara, katakata, dan gerakan anggota tubuh orang lain (O'Connor, 2001).

Para praktisi NLP banyak mengunakan teknik dari psikologi dan psikoterapi. Beberapa teknik yang paling sering digunakan adalah submodalitas, anchoring, swish pattern, reframing dll.

Submodalitas Ada dua tipe submodalitas: analog dan digital. Submodalitas digital adalah off atau on. Misalnya, suatu gambar mental berada dalam posisi apakah bergerak atau diam. Tidak ada posisi tengah. Di sisi lain, submodalitas analog sangat bervariasi di antara ujung-ujung paling ekstrim. Bunyi bervariasi sepanjang kondisi diam/hening/senyap hingga nyaring.

Mayoritas submodalitas adalah analog, hanya beberapa yang digital.Kata-kata yang digunakan seseorang bisa mengungkap bagaimana ia merepresentasikan hal-hal secara internal. Hal ini juga berlaku dalam submodalitas. Beberapa contoh khasnya adalah, "Saya mendengar Anda dengan sangat jelas dan nyaring." Atau "Kita baru menggali permukaanya". Atau "Masa depannya masih suram". Hal-hal yang kita ucapkan sering mencerminkan tidak hanya predikat-predikat spesifik indrawi tetapi juga sub-sub-modalitas terkait. Mereka memberi pendalaman lebih persis terhadap apa yang sedang dipikirkan orang dan bagaimana mereka mengodekannya secara internal.

$\begin{array}{rrr}\text { Hubungan } & \text { seperti ini juga } \\ \text { kadang-kadang } & \text { tampak } & \text { dalam }\end{array}$

komunikasi non verbal. Misalnya, orang sering mengindikasikan tempat yang pasti atas gambaran di mata otaknya dengan cara menunjuk langsung. Atau menggunakan tangan untuk mendefiniskan bentuk sesuatu. Memahami submodalitas berguna untuk Anda bisa memilih cara mengodekan masa lalu dan masa depan Anda. Dalam melakukan itu, Anda bisa mengubah pemaknaanya dan membuat memori atau impian itu menjadi lebih intens, kredibel, gampang dikenang, dan diinginkan, atau sebaliknya-menjadi kurang intens, kredibel, dikenang, dan diinginkan.

Anchoring, Anchor berarti jangkar. Jangkar adalah, nada suara atau sentuhan tapi bisa merupakan visual yang unik, auditori, kinestetik, atau rangsangan penciuman (gustatory). Anchoring adalah proses dimana suatu keadaan tertentu atau respon dikaitkan (berlabuh) dengan jangkar unik. Teknik NLP dari anchoring ini dipinjam dari prinsip pengkondisian klasik, sebagaimana dikembangkan oleh IP Pavlov, seorang psikolog Rusia sekitar 100 tahun yang lalu. Seorang psikoterapis mungkin menjangkar keadaan positif seperti ketenangan dan relaksasi, atau keyakinan dalam pengobatan fobia dan kecemasan, 
seperti berbicara di depan umum (Biswal \& Prusty, 2011). Jadi anchoring dipakai untuk mengatasi masalah saat ini untuk digunakan dimasa yang akan datang.

Swish Pattern, Swish adalah proses mengganggu pola pikiran dari satu yang mengarah ke perilaku yang tidak diinginkan ke salah satu yang mengarah pada perilaku yang diinginkan. Hal ini melibatkan memvisualisasikan sebuah 'isyarat' yang merupakan bagian dari perilaku yang tidak diinginkan. Misalnya, tangan perokok dengan rokok bergerak ke arah wajah, dan kemudian 'beralih' ke visualisasi dari hasil yang diinginkan, seperti orang terlihat sehat, energik dan bugar.

Framing Framing adalah proses dimana unsur komunikasi disajikan sehingga menggeser persepsi individu tentang makna atau "frame" dikaitkan dengan kata, frasa dan peristiwa. Framing adalah dasar dari lelucon, mitos,legenda, dongeng dan cara paling kreatif dalam berpikir (O 'Connor, 2001). Konsep ini berbeda dengan sejumlah terapi sebelum NLP (Sharpley, 1987). Framing membantu mengubah tanggapan dan perilaku dengan mengubah cara peristiwa tersebut dilihat. Jadi framing adalah cara untuk mengganti makna suatu peristiwa dengan pemaknaan yang baru yang lebih positif.
Six step framing,kegiatan ini merupakan kelanjutan dari kegiatan ketiga Framing. Partisipan diajak untuk mengidentifikasikan masalah yang ingin diselesaikan. Kemudian membangun komunikasi dengan bagian yang bertanggung jawab terhadap perilaku tersebut. Setelah membangun komunikasi maka partisipan mengajak masalah-masalah yang diselesaikan untuk berdialog, bertujuan untuk menghasilkan "outcome" yang disetujui semua "bagian" dan hasilnya bermanfaat bagi partisipan bersangkutan dan pengaruh terapi NLP terhadap peserta didik

\section{SIMPULAN}

Bedasarkan paparan atau penjelasan di atas, dapat dikatakan Neuro-Linguistic Programming (NLP) merupakan program yang memanfaatkan diri sendiri untuk menyelesaikan suatu permasalahan dengan melihat proses munculnya permasalahan tersebut. NLP dalam pembelajaran dapat memudahkan individu dalam berpikir rasional dan memiliki perasaan yang tepat. Berikut beberapa teknik dalam NLP yang dapat diterapkan dalam layanan konseling diantaranya reframing, anchoring, dan building rapport.

\section{DAFTAR PUSTAKA}

Abdivarmazan, M. \& Sylabkhori, Z. 2016. Effectiveness of training of 
Neuro-linguistic programming (NLP) strategies on reducing social anxiety. World Scientific News (Online) 60, 2016, 67-77

Albalawi, K.S. 2014. Effectiveness of Neuro-Linguistic Programming on Enhancing Univerity Student' Quality of Life. International Journal of Arts \& Sciences (Online) 7(6), 2014, 431- 442 (http://www.proquest.com, 10 Februari 2017)

Kusuma, A. P. 2017. Implementasi Model Pembelajaran Student Teams Achievement Division dan Team Assisted Individualization ditinjau dari Kemampuan Spasial Siswa Al-Jabar. Jurnal Pendidikan Matematika Vol. 8, No. 2, 2017, Hal 135 -143.

Knight, S. 2002. NLP AT WORK Neuro Linguistic Programming The Difference that Makes a Difference in Business (2nd ed). London: Nicholas Brealey Publishing.

Lashkarian, A., \& Sayadian, S. 2015. The Effect of Neuro Linguistic Programming (NLP) techniques on young Iranian EFL learners' motivation, learning improvement, and on teacher's. Procedia-Social and Behavioral Sciences (Online) 199, 2015, 510-516

Rahmawati,N.K. 2014. Eksperimentasi Model Pembelajaran TTW dan NHT pada Materi Bangun Ruang Sisi Datar Ditinjau dari Kemampuan
Komunikasi Matematis Siswa. Tesis. Surakarta: UNS.

Palmer, S. (Ed). 2000. Introduction to Counselling and Psychotherapy The Essential Guide. London: SAGE Publications.

O'Connor, J. (2001). NLP WORKBOOK: A Practical Guide of Achieving the Results You Want. London: Thorsons.

O'Connor, J. \& Seymour, J. 1990. Introducing NLP: Neuro-Linguistic Programming (Rev. ed.). California: The Aquarian Press.

Pintos, I. \& López. 2010. CHOICES AND RESPONSIBILITY IN COUNSELING: Looking into NeuroLinguistic Programming (NLP) and Reality Therapy (RT) for a Common Thread. International Journal of Choice Theory and Reality Therapy (Online) Vol. XXX, No. 2, 2010, 23- 35

Ready, R. \& Burton, K. 2010. NeuroLinguitic Programming for Dummies (2nd ed). England: John Wiley \& Sons, Ltd. Sutton, J. \& Stewart, W. (2002). Learning to Counsel Develop the Skills You Need to Counsel Others (2nd ed). UK: How To Books Ltd.

Syamsul Hidayat. 2016. Peranan Media Pembelajaran Berbasis Budaya Lokal Terhadap Peningkatan Pelaksanaan Konseling AUD. Prosiding Seminar Nasional Revitalisasi Nasionalisme Melalui Konseling 
Berbasis Kearifan Lokal Sejak Usia Dini, IKIP PGRI, Jember, 2426 Maret 2016.

Biswal dan Prusty. 2011. Trends in neurolinguistic programming (NLP): $A$ critical review. Social science international, Vol. 27; No.1. 41-58.

Davies, Roderique-Gareth. 2009. Neurolinguistic programming : cargo cult psychology?. Journal of applied research in higher education. Vol 1. 57-63.

Huehls, Frances. 2010. Literature review. International of journal of educational advancement. Vol 10. 48-55.

Seyhener, Lidy. 2011. Time line therapy. An advanced technique from the science of neurolingistic programming. Australian journal of clinical hypnotherapy and hypnosis. 31. 1

Stipanic, M. 2010. Effect of neurolinguistic psychotherapy on psychological difficulties and perceived quality of life. Counselling and psychotherapy research. 10 (1).

Tosey, P. 2005. Mapping transformative learning the potential of neurolinguistic programming. Journal of transformatic education. 3 (2) 140167. 